\title{
REVISANDO LIVROS DIDÁTICOS DE HISTÓRIA: ação da diplomacia cultural em nome da paz
}

\author{
Juçara Luzia Leite*
}

\section{Resumo}

No cenário internacional do pós-primeira guerra, gradualmente, os objetivos morais somavam-se aos objetivos cívicos do ensino de História. A década de 1920, especialmente, foi marcada por uma discussão ampla sobre o papel da educação - especialmente do ensino de História - na construção de um mundo de paz. O livro didático esteve no centro desse debate e educadores de tendências opostas manifestaram-se. Ao longo desses debates, o papel da Commission Internationale de Coopération Intellectuelle (CICI) se destacou na Liga das Nações, procurando facilitar a colaboração de intelectuais no serviço de promoção da paz mundial dentro dos objetivos da Liga. O presente artigo reflete sobre esse contexto, destacando o papel do Brasil na adoção de uma diplomacia cultural válida tanto para os países europeus quanto para os vizinhos latino-americanos, considerando a dinâmica da transição do foco de interesses da Liga das Nações para a União Pan-americana. Ressaltamos a atuação do Ministério das Relações Exteriores nesse processo ao empreender uma diplomacia cultural sobre a História a ser ensinada, que, incólume às oscilações políticas do período, culmina na manutenção de publicação da "Bibliografia de História do Brasil”.

Palavras-chave: Ensino de História. Livro didático. Diplomacia cultural. Liga das Nações. União Panamericana.

\section{Introdução: ensino de história e revisão moral}

A década de 1920 foi marcada por uma discussão ampla sobre o papel da educação especialmente do ensino de História - na construção de um mundo de paz. O livro didático esteve no centro desse debate e educadores de tendências opostas manifestaram-se, destacando-se a presença cada vez maior dos EUA. De acordo com a UNESCO (1950),

\footnotetext{
*Doutora em História Social pela Universidade de São Paulo - USP. Professora Associada da Universidade Federal do Espírito Santo - UFES. E-mail: jujuluzialeite@gmail.com
} 
algumas organizações internacionais não governamentais se incumbiram de protagonizar pesquisas sobre manuais escolares de diferentes países, considerando especialmente os contextos francês, alemão e espanhol. ${ }^{1}$ Em 1921, por exemplo, o Carnegie Endowment for International Peace realizou uma pesquisa sobre as causas da $1^{\text {a }}$ Guerra e sobre as imagens que os países veiculavam de si e dos outros nos livros didáticos, focando especificamente o caso dos EUA.

No cenário internacional do pós-primeira guerra, gradualmente, os objetivos morais somavam-se aos objetivos cívicos do ensino de História. No período de 1908 a 1934, foi realizada uma série de Congressos Internacionais de Educação Moral. Durante o $3^{\circ}$ Congresso (Genebra, agosto de 1922), por exemplo, o ensino de História foi amplamente debatido sob uma perspectiva internacionalista. A tendência militarista dada ao ensino dessa disciplina foi denunciada por muitos congressistas. Anos depois, durante o $5^{\circ}$ Congresso (Paris, setembro de 1930), foi determinado que o ensino de História deveria se tornar cada vez mais voltado para uma concepção de ensino de acordo com um "espírito internacional” (CICCHINI, 2004).

A Liga das Nações não estava ausente desse debate, destacando-se o papel da Commission Internationale de Coopération Intellectuelle (CICI). Ainda que o objetivo da CICI não tenha sido eminentemente educacional, ocupou-se de questões da educação, sobretudo se interessando pela análise dos livros didáticos. É interessante notar que a CICI estava diretamente ligada ao Conselho da Liga das Nações, órgão restrito, cuja incumbência principal era a gerência da paz (a Liga - que nascera como proposta multilateral de organização racional das relações internacionais e de constituição do Direito Internacional, a partir dos 14 pontos apresentados pelo presidente americano Wilson na Conferência de Paz de 1919 -, era constituída por três órgãos principais: o Conselho, a Assembleia, e o Secretariado).

O Brasil, como lutara na $1^{\text {a }}$ Guerra Mundial, participou da Conferência de 1919 em Paris defendendo a possibilidade de inserção, na recém-criada Liga, de Estados que não configuravam entre as grandes potências. Por conta da atuação da diplomacia brasileira na Conferência de 1919, o Brasil integrou a Comissão da Liga das Nações, com Epitácio Pessoa como chefe da delegação, cujo trabalho foi fundamental para a indicação do país como membro temporário (rotativo) do Conselho.

\footnotetext{
${ }^{1}$ Esse trabalho de revisão da trajetória histórica da adequação dos livros didáticos "para a paz”, protagonizado pela Unesco, gerou, em 1952, o documento "Étude sur les manuels scolaires d'histoire et de geographie". Disponível em: <http://unesdoc.unesco.org/images/0012/001261/126100fb.pdf>.
} 
Eleito em 1921 como membro rotativo do Conselho da Liga, o Brasil manteve-se, até 1926, postulando um assento permanente. Em 1924, como parte dessa campanha, foi criada uma Missão de Representação Permanente na Liga, que logo foi elevada à categoria de Embaixada, destacando-se, nessa empreitada, o trabalho de Afrânio de Mello Franco. Alexandra de Mello e Silva (1998, p. 149-150) afirma que:

\begin{abstract}
A argumentação da diplomacia brasileira baseava-se, então, no prestígio internacional de que o país já desfrutava, produto de atributos nacionais (dimensões continentais e demográficas, peso dentro da América do Sul); de uma já consolidada tradição diplomática (pacifismo, defesa da igualdade soberana das nações, respeito ao Direito Internacional) e mesmo do fato de ter sido a única nação latino-americana de participar militarmente da I Guerra Mundial. Desse ponto de vista, a candidatura brasileira se apresentava como 'natural', tendo em vista a posição única ocupada pelo país na América do Sul e suas fortes ligações com os EUA e a Europa, que lhe conferiam uma posição de prestígio dentro da Liga.
\end{abstract}

Outra análise do contexto foi realizada por Baracuhy (2006, p. 357) que afirma que uma "comunidade de poder" iria substituir o “equilíbrio de poder”. O autor acredita que foi nesse contexto que o regime republicano brasileiro enfrentou o seu "[...] batismo de fogo internacional, com o desafio de fazer política externa à sombra do Barão”.

Interessando-se particularmente pela questão das minorias nos países do oriente europeu, a atuação do Brasil no Conselho da Liga ia além da função de mero relator em questões europeias. Examinou e votou sobre assuntos de questão jurídica, codificação do direito internacional, higiene, dentre outros, mas, especialmente, a cooperação intelectual e a educação. De acordo com Jean-Jacques Renoliet (1999), embora o "Pacto da Liga das Nações” não expusesse nenhuma cláusula relativa à cooperação intelectual, seu Conselho adotou, em 1921 (apesar da hesitação inglesa), uma proposta francesa que respondia às demandas de diferentes associações internacionais favoráveis à extensão do papel da Liga a favor da consolidação da paz mundial.

\title{
Uma diplomacia cultural
}

Oficialmente criada em janeiro de 1922, a CICI constituiu o primeiro passo da Organisation de Coopération Intellectuelle (OCI), uma das organizações técnicas da Liga das Nações. A OCI compreendia também as Commissions Nationales de Coopération Intellectuelle (1923), o Institut International de Coopération Intellectuelle (IICI, 1925), o 
Institut International du Cinématographe Éducatif (IICE, 1928), além de diferentes organismos especializados e comitês de especialistas. Segundo a análise de Renoliet (1999), o Institut International de Coopération Intellectuelle (proposto pela França em 1924) também exercia o papel de fomentador da influência cultural e política francesa. Destaca-se o fato de que o estatuto do IICI lhe garantia autonomia em relação à Liga das Nações e ao governo francês, permitindo-lhe relações diplomáticas com as diferentes Nações que lá possuíam delegados.

A Organisation de Coopération Intellectuelle (OCI), por sua vez, procurou, por meio do Institut International de Coopération Intellectuelle, facilitar a colaboração de intelectuais no serviço de promoção da paz mundial dentro dos objetivos da Liga das Nações. De fato, o trabalho essencial do IICI consistia mesmo em pesquisas que, algumas vezes, resultaram em ações promovidas por associações - privadas ou não -, nos diferentes campos da ação intelectual, tais como, conforme destaca Renoliet (1999): o desarmamento moral por meio do ensino dos princípios da Liga das Nações, da revisão de livros didáticos e do uso pacífico do cinema e do rádio; uma sistematização do ensino com a equivalência de diplomas, intercâmbio de professores e estudantes, e criação de centros de documentação pedagógica; coordenações em diferentes campos científicos; tradução de obras literárias; conservação e proteção internacional de obras de arte, colaboração entre bibliotecas e arquivos; e a defesa dos direitos intelectuais.

A partir de 1930, o Institut International de Coopération Intellectuelle foi encarregado de conduzir uma pesquisa sobre os livros didáticos de História que se referia, no que diz respeito ao ensino de História, tanto às ações dos países e organizações internacionais, quanto às regras adotadas pelas diferentes nações para a escolha dos livros didáticos. De acordo com Giuntella (2003), essa pesquisa foi publicada pela Liga das Nações, em 1932, com o título “A revisão dos manuais escolares”. Disso resultou a inclusão, em 1932, de uma rubrica consagrada especificamente para a revisão dos livros didáticos de História no Boletim da Cooperação Internacional do IICI (RENOLIET, 1999).

Além da Commission Internationale de Coopération Intellectuelle, também o Bureau International d’Éducation (BIE) - do Instituto Jean-Jacques Rousseau, de Genebra -, fundado em 1925, destacou-se na tarefa de revisão dos livros didáticos de História e reuniu uma série de projetos elaborados em nível internacional entre o final do século XIX e o início do século XX. De acordo com Giuntella (2003), seu objetivo era centralizar e coordenar a documentação educativa e obras destinadas à formação dos professores. Em 1938, o BIE publicou, sob o título de Élaboration, utilization et choix des manuels scolaires: d'après les 
données fournies par les Ministères de l'Instruction publique, o resultado de pesquisa realizada em diferentes Ministérios da Educação sobre a interferência do Estado na escolha de livros didáticos de História e sobre a existência de instituições governamentais específicas para a produção dos livros (BECHET, 2008).

Desligado da Liga das Nações a partir de 1926, o Brasil, por meio de seus representantes diplomáticos, adotou, cada vez mais, uma postura pan-americanista, não se afastando, entretanto, totalmente dos debates da Liga, dispondo-se a participar, sempre que convidado, das conferências e trabalhos promovidos pela Liga (a chamada "colaboração desinteressada). Deve-se notar, todavia, que o Brasil manteve-se ligado ao IICI, subvencionando as suas obras. Para Dumont (2010), essa escolha brasileira de permanecer ligado ao IICI mesmo desligado da Liga era justificada pela necessidade de conferir um determinado "prestígio moral” válido tanto para os países europeus quanto para os vizinhos latino-americanos, além de permitir ao Brasil permanecer presente no cenário diplomático europeu.

O deslocamento cada vez maior do foco das relações diplomáticas brasileiras da Europa para as Américas pode ser verificado desde a atuação do Barão do Rio Branco (como político e intelectual - à frente do Ministério das Relações Exteriores desde 1902 e do Instituto Histórico e Geográfico do Brasil a partir de 1908). Note-se que o IHGB já colaborava com o Ministério das Relações Exteriores desde o governo de Prudente de Morais (alçado à presidência de honra do Instituto) cedendo peças de seu acervo documental (GUIMARÃES, 2007). Empenhado em marcar um lugar de liderança do Brasil nos assuntos latino-americanos, intensificou o intercâmbio com instituições científicas da Europa e EUA. Em decorrência dessa política, o IHGB passou a receber um maior número de colaboradores e membros estrangeiros (GUIMARÃES, 2007). Dessa forma, concordamos com Santos (2010) quando afirma que a ação do Brasil na Liga foi um desdobramento de práticas de política externa plantadas por Rio Branco que incluía, dentre outras ações, a organização de Congressos Internacionais como forma de valorizar o intercâmbio intelectual.

Ao sair da Liga das Nações, mas em dia com os debates internacionais e tendo a pretensão de destacar-se na diplomacia sul-americana, o Brasil também se articulava na promoção de um ensino de História condizente com as discussões de então. A circulação de ideias verificada permite-nos trazer uma nova compreensão a partir desse contexto: a atuação do Ministério das Relações Exteriores na normatização de uma História a ser didatizada como repercussão da ação de determinados intelectuais (políticos e professores) empenhados na consolidação de representações de um Brasil pacífico e civilizado (LEITE, 2011). Foi nesse 
contexto, em plena afirmação do Governo Vargas, que nasceu o "Convênio entre o Brasil e a República Argentina para a Revisão dos Textos de Ensino de História e Geographia”.

\title{
Revisão dos textos para o ensino de história
}

O “Convênio entre o Brasil e a República Argentina para a Revisão dos Textos de Ensino de História e Geographia” foi assinado em 1933, por ocasião de visita ao Brasil do presidente argentino, General Agustín P. Justo, como consequência dos votos emitidos, em 1928, durante o X Congresso de História Nacional realizado em Montevidéu. Na ocasião, foram nomeados plenipotenciários por seus respectivos chefes de governo, o brasileiro Afrânio de Mello Franco e o argentino Carlos Saavedra Lamas.

Afrânio de Mello Franco era o ministro de Estado Brasileiro das Relações Exteriores e ex - embaixador brasileiro na Liga das Nações. Carlos Saavedra Lamas era o ministro Argentino das Relações Exteriores e Culto, posteriormente, em 1936, presidiu a Assembleia da Liga das Nações, ano em que recebeu o Nobel da Paz.

Era um contexto em que, na América do Sul, buscava-se um consenso sobre as fronteiras e a estabilidade na região do Prata. Essa concorrência era também materializada pela competição entre os acordos e debates do IICI e os diferentes projetos de cooperação intelectual promovidos pela União Pan-americana. ${ }^{2} \mathrm{O}$ Brasil, nesse sentido, estava preocupado com a influência argentina sobre os países vizinhos. De acordo com Garcia (2005, p. 51):

\begin{abstract}
A rivalidade com a Argentina, aliás, não se limitava à luta pela supremacia regional, mas se estendia à competição por prestígio internacional na Europa e, em particular, na Liga das Nações. Parecia que o país já tinha alcançado o seu ponto ótimo de desenvolvimento econômico, como país 'essencialmente agrícola', pouco restando a fazer senão garantir a defesa nacional contra agressões externas (o que alimentava certa preocupação defensiva na área militar) e desfrutar, com indisfarçável regozijo, dos ganhos simbólicos em termos de prestígio advindos da participação brasileira na Conferência da Paz de Paris.
\end{abstract}

Somados à disposição internacional para a revisão de livros didáticos protagonizada especialmente pela Liga das Nações, os debates sobre conflitos e disputas territoriais sulamericanas marcaram o momento em que os governos de Brasil e Argentina perceberam a importância de juntar esforços para a educação de gerações futuras em nome da paz. (LEITE,

\footnotetext{
${ }^{2}$ Sobre as concorrências entre o IICI e a União Pan-americana, ver o recente estudo de Dumont (2010).
} 
2011)

O Convênio tornou-se Decreto em 1934, e Documento do Ministério das Relações Exteriores em 1936. Somente, então, o Itamaraty constituiu a Comissão Brasileira Revisora dos Textos de Ensino de História e Geografia que aprovou as “Normas” estabelecidas para o cumprimento do Convênio. (LEITE, 2010) ${ }^{3}$.

Especificamente em relação aos livros didáticos de História, a Comissão Brasileira determinou normas constituídas pelos seguintes critérios de análise e revisão: a) generalidade - definido como proporção conveniente entre as diferentes seções nas quais a História é dividida, com o objetivo de produzir visão imparcial dos fatos; b) cordialidade recomendação explícita contra “[...] comentários deprimentes de referência a povos estrangeiros”; c) solidariedade - orientação para o desenvolvimento de capítulos que contemplem as relações de paz e comércio entre o Brasil e demais nações; d) idealismo instrução para que os livros didáticos de História destaquem a política exterior brasileira como idealista e possuidora de coerentes; e) americanidade - atenta ao necessário destaque das relações interamericanas, com ênfase em “[...] atitudes, iniciativas e fatos, que formam a consciência americanista da nossa civilização e constituem uma segurança dos destinos pacíficos do novo mundo”; f) veracidade - critério que parte do pressuposto da existência de uma veracidade histórica e determina que “[...] as suas sínteses excluirão sistematicamente dos temas controversos comentários e divagações, limitando-se à indicação dos fatos”. Em relação aos assuntos internacionais, recomenda que se evitem as “[...] qualificações ofensivas e os conceitos que atinjam a dignidade dos Estados e os seus melindres nacionais”.

Curiosamente, em relação aos compêndios de Geografia, a Comissão definiu uma única recomendação e critério de análise: “Os compêndios de geografia deverão conter as estatísticas oficiais mais modernas e sempre estabelecer uma noção aproximada da riqueza e capacidade de produção dos Estados estrangeiros”.

A partir do Decreto-Lei 1.006, de 30 de dezembro de 1938, ficaram estabelecidas as condições de produção, importação e utilização dos livros didáticos, bem como a criação de uma Comissão Nacional do Livro Didático (CNLD), vinculada ao Ministério da Educação e Saúde. O Ministério das Relações Exteriores deixava de ser, a partir de então, a instância

\footnotetext{
${ }^{3}$ A cópia oficial do Decreto n ${ }^{\circ}$ 24.395, de 13 de junho de 1934, que "Promulga o Convênio entre o Brasil e a República Argentina para a revisão dos textos de ensino de História e Geografia, Rio de Janeiro, 10 de outubro de 1933” está disponível em http://www2.mre.gov.br/dai/b_argt_28_563.htm. Para efeitos de nossa investigação, estamos utilizando o Documento do Ministério das Relações Exteriores Brasileiro, publicado em 1936 pela Imprensa Nacional e intitulado Convênio entre o Brasil e a República Argentina para a revisão dos textos de ensino de História e Geographia, exemplar disponível no Real Gabinete Português de Leitura (Rio de Janeiro).
} 
avaliadora e reguladora dos textos para o ensino de História.

Merece destaque, ainda, o fato de que o Brasil, logo após firmar o Convênio com a Argentina, firmou um outro com o México, reproduzindo o primeiro na sua essência. $\mathrm{O}$ “Convênio entre o Brasil e os Estados Unidos Mexicanos para a Revisão de Textos de Ensino de História e Geografia” foi celebrado em 28 de dezembro de 1933, mas só entrou em vigor a partir de 3 de dezembro de 1934. Foi a base para o Decreto n. ${ }^{\circ}$ 2245, de 4 de janeiro de 1938, e fez parte da Missão Alfonso Reyes, embaixador mexicano no Brasil, de expansão das relações culturais entre os dois países (LEITE, 2010).

Como desdobramento do Convênio com a Argentina, iniciaram-se publicações de autores argentinos, traduzidos para o português, respeitando os termos do Convênio. Reciprocamente, também foram publicados autores brasileiros na Argentina, devidamente traduzidos para o espanhol. A iniciativa de tais publicações coube ao Ministério das Relações Exteriores. As publicações consistiam em coleções abertas por um volume relativo à História do outro país. Dessa forma, no caso argentino, o livro de abertura escolhido para representar o País na "Coleção brasileira de autores argentinos”, seguindo as Normas do Convênio, foi a “Síntese da história da civilização argentina”, de Ricardo Levene. No caso brasileiro, abrindo a "Biblioteca de autores brasileiros" foi publicada a "História da civilização brasileira”, de Pedro Calmon. Os livros publicados para comporem as coleções não versavam apenas sobre História, mas também sobre temas sociológicos, além de obras literárias, como, por exemplo, “Os Sertões”, de Euclides da Cunha, e "Facundo", de Sarmiento. Segundo a descrição de Hollanda (1957, p. 205):

As Comissões Brasileira e Argentina Revisoras dos Textos de História e Geografia, que tinham, respectivamente, como relator e presidente os historiadores Pedro Calmon e Ricardo Levene, não encararam a publicação de obras de geografia, disciplina a respeito da qual o Convênio se mostrava, aliás, mui lacônico. A ‘Coleção Brasileira de Autores Argentinos' foi iniciada, em 1938, pelo Serviço de Cooperação Intelectual do Ministério das Relações Exteriores, que assumiu a sua distribuição. Na Argentina, a 'Biblioteca de Autores Brasileiros', que abarcou maior número de obras, foi entregue a uma editora particular, que lhe deu esmerada apresentação material.

Em 1943, foi criada, no Ministério das Relações Exteriores, a Comissão de Estudo dos Textos de História do Brasil (CETHB). Em 1945, outra portaria reorganizava a Comissão que passava a ter seis membros com as atribuições de conhecer a bibliografia sobre a História do Brasil - editada no Brasil ou no exterior -, preparar lista bibliográfica contendo as principais obras sobre os assuntos históricos brasileiros e apresentar pareceres sobre questões de História 
do Brasil.

Dessa forma, a partir de 1944, foram publicadas semestralmente relações intituladas "Bibliografia de História do Brasil”. O volume primeiramente publicado referia-se ao $2^{\circ}$ semestre de 1943. Hollanda (1957) observa que, a partir de 1947, a "Bibliografia” passou a ser publicada anualmente no formato de fascículo, mas que a periodicidade não foi regular. Assim sendo, o conjunto dos volumes até esse período foi formado por: $2^{\circ}$ semestre de 1943 (publicado em 1944); $1^{\circ}$ semestre de 1944 (publicado em 1944); $2^{\circ}$ semestre de 1944 (publicado em 1945); $1^{0}$ semestre de 1945 (publicado em 1945); $2^{\circ}$ semestre de 1945 (publicado em 1946); $1^{\circ}$ e $2^{\circ}$ semestre de 1946 (publicado em um só volume em 1947).

O autor adverte também que "Cumpre observar que, embora incluídos na Bibliografia, os compêndios nacionais de História não têm sido objeto de resenhas críticas” (Hollanda, 1957, p. 208). De qualquer forma, a "Bibliografia” foi publicada e circulou interruptamente até 1971, tratando-se também de fonte privilegiada para a análise de representações e protocolos de escrita (CHARTIER, 2001).

\section{Uma história "correta” a ser didatizada}

A organização da "Bibliografia” ficou sob a responsabilidade da Comissão de Estudo dos Textos da História do Brasil, que foi inicialmente composta por Pedro Leão Veloso (presidente), Rodolfo Garcia, Heitor Lyra, E. F. de Sousa Docca, Helio Vianna e Luiz Camillo de Oliveira Netto. A brochura era dividida em quatro seções: Obras, Opúsculos, Publicações periódicas e seriadas, e Trabalhos incluídos em publicações periódicas.

A partir de 1947, no início de cada volume, foram impressas as atribuições da Comissão de acordo com a Portaria de 26 de julho de 1945. Os membros da Comissão passaram a ser: Raul Fernandes (presidente), Hildebrando Pompeu Pinto Accioly, Joaquim de Sousa Leão Filho, Rodolfo Garcia, Luiz Camillo de Oliveira Netto, Hélio Vianna e José Honório Rodrigues.

Em 1951, os volumes passam a se organizar em novas seções: Obras editadas no Brasil, Obras editadas em pais estrangeiro, Publicações periódicas e seriadas nacionais, Publicações periódicas e seriadas estrangeiras, e Artigos incluídos em publicações periódicas e jornais. Na ocasião, a Comissão era formada por: Raul Fernandes (até $1^{\circ}$ de fevereiro de 1951) sucedido por João Neves da Fontoura (até 22 de março de 1951) e seguido pelo interino Heitor Lyra - presidentes; e Heitor Lyra, Luiz Camillo de Oliveira Netto, Hélio Vianna, José 
Honório Rodrigues, Pedro Freire Ribeiro e Américo Jacobina Lacombe - membros. No volume relativo aos $1^{\circ}$ e $2^{\circ}$ semestre de 1951, constam alguns livros didáticos como, por exemplo, o “Questionários de Geografia, História e Ciências para o $4^{\circ}$ ano primário”, de Déborah Pádua Mello, com 60 páginas (Bauru, 1951); e o "História administrativa e econômica do Brasil para as escolas técnicas e cursos comerciais”, de Basílio de Magalhães (Rio, 1951).

Consta no Ministério das Relações Exteriores que 14 volumes da "Bibliografia” foram publicados no período de 1944 a 1958. Em 1959, uma nova Portaria reorganiza a Comissão ${ }^{4}$ que passa a ser presidida pelo próprio Ministro e a ser composta por doze membros (um dos quais indicado pelo IHGB). Suas competências estavam assim descritas:

V - Compete à Comissão:

a) tomar conhecimento da bibliografia histórica nacional, editada no Brasil ou no exterior, constante de obras gerais ou de artigos divulgados em publicações periódicas;

b) preparar uma relação bibliográfica das principais obras e artigos sobre assuntos históricos brasileiros, com resumo dos aspectos de maior interesse e transcrição de trechos de excepcional importância;

c) rever em vista dos dados de comprovada segurança e autenticidade, as informações compendiadas nos impressos sobre assuntos históricos, assinalando as inexatidões porventura encontradas.

d) apresentar pareceres sobre questões da história nacional, relacionadas com a política exterior do país quando solicitados pelo Ministro de Estado;

e) organizar os Anais do Itamaraty, para sua publicação periódica, bem como quaisquer outras publicações relativas à História do Brasil, e em especial a assuntos diplomáticos;

f) organizar instruções para orientar pesquisas em Arquivos estrangeiros a serem feitas por funcionários das Missões Diplomáticas brasileiras, estudar o material resultante dessas pesquisas e propor ao Ministro de Estado o destino que ao mesmo deva ser dado e a parte que o Itamaraty deverá conservar em seus Arquivos ou publicar na conformidade com a Portaria de 19 de janeiro de 1956 (BRASIL, Portaria 15/69 do MRE).

Da “Bibliografia” publicada em 1971 e referente ao período de 1959/1969, constam publicações didáticas da História em maior evidência que nas anteriores, como, por exemplo, os livros de Carolina Renno Ribeiro de Oliveira:

- Questionário de História do Brasil e Geografia (perguntas e respostas). 11 $11^{\mathrm{a}}$ ed. (atual. com estudos sobre Brasília e o Estado da Guanabara). São Paulo: graf. Biblios, 1960. 180p. il. map.

- Moderno questionário de História do Brasil e Geografia $5^{\circ}$ e $6^{\circ}$ anos primários e

\footnotetext{
${ }^{4}$ Portaria no 15 de 14 de abril de 1959, publicada no D.O.U. em 29 de abril de 1959.
} 
preparatórios em geral... 30 ed. São Paulo: Ed. Do Mestre, 1968. 254p. il.

- Moderno questionário de História do Brasil e Geografia $5^{\circ}$ e $6^{\circ}$ graus, admissão e preparatórios em geral. 31ª ed. Dão Paulo: Ed. Do Mestre, 1969, 254p. il. map.

E também livros de História Regional para fins didáticos como o “Textos de História e Geografia do Espírito Santo”, de Renato José Costa Pacheco, com 62 páginas mimeografadas (Vitória, 1967).

Observamos, assim, a manutenção de algumas práticas do Ministério das Relações Exteriores no que diz respeito a seu papel na revisão de textos para uma História a ser didatizada, não obstante as oscilações políticas. Pensamos que, desde a atuação do Brasil na Liga, e, posteriormente, em decorrência do necessário investimento em uma política panamericana, o Brasil necessitava consolidar representações de si mesmo como um país pacífico, equilibrado e justo. O ensino de História era uma ferramenta importante nesse processo. Após a $2^{\mathrm{a}}$ Guerra, com a criação de uma Comissão específica para revisar livros didáticos de diferentes disciplinas escolares no âmbito do Ministério da Educação, o Ministério das Relações Exteriores manteve sua atenção na divulgação de uma História do Brasil dada a ler por meio da publicação de uma "Bibliografia” orientadora de uma História correta a ser divulgada. Isto é, manteve sua atuação no processo de recomendações diplomáticas que visavam a revisão de textos também escolares de História, bem como a regulação e o controle da História escrita.

Atentamos, por fim, para o fato de que, em um momento em que a historiografia atual aproxima o cultural e o político, é preciso destacar a importância do Arquivo Histórico do Itamaraty no Rio de Janeiro para a renovação das pesquisas sobre diplomacia cultural. Merecem relevo as seções Missões diplomáticas - embaixadas, Missões especiais do Brasil no estrangeiro, Congressos e conferências internacionais, Organismos Internacionais, Diversos no Exterior e Correspondência especial. As atas e relatórios das delegações brasileiras na III Conferência Interamericana de Educação, na VIII Conferência Mundial de Educação, na Conferência Mundial para o Desarmamento, são exemplos dos documentos que fazem parte desse conjunto, bem como a correspondência de J. C. Macedo Soares em missão especial na Itália em 1932, e os ofícios à União Pan-americana (1931-40).

Concluímos, com as reflexões aqui expostas, que intentar produzir um futuro de paz, eliminando dos livros didáticos representações que levassem a expressões de preconceitos entre nações, conduzia ao risco de submeter a História escrita a critérios transitórios e meramente políticos, sem a garantia de logro, e isso não passou despercebido pelos 
intelectuais do período. Analisar iniciativas como o "Convênio entre o Brasil e a República Argentina para a Revisão dos Textos de Ensino de História e Geografia”, hoje, leva-nos também a refletir sobre como a geração de intelectuais, políticos e professores daquele contexto depositaram esperanças e responsabilidades em si mesmos, atribuindo-se uma missão fraternal, e à História a projeção do porvir. Em suma, na fronteira da História Política e Cultural, nosso estudo espera contribuir à compreensão da necessária e sensível articulação entre relações exteriores e história ensinada e construída por intelectuais que negociaram a história em nome da Paz.

\title{
REVIEWING HISTORY SCHOOLBOOKS: Cultural diplomacy action to foster peace
}

\begin{abstract}
In the post WWI scenario, moral objectives were gradually joined to civic ones in the teaching of History. The 1920s were particularly marked by a comprehensive discussion about the role of education - mainly the teaching of History - in building world peace. School books were at the heart of this debate, where educators and opposite trends were able to voice their opinions. During these debates, the role of the Intellectual Cooperation International Commission (CICI) was outstanding in the League of Nations, the goal of which was to facilitate the collaboration of intellectuals working to foster world peace within the scope of the League's objectives. This article addresses this context, emphasizing the role of Brazil in the adoption of a valid cultural diplomacy, both for European and Latin American countries, considering the change of focus from the interests of the League of Nations to the Pan-American Union. The participation of the Foreign Relations Ministry in this process is highlighted in this study, in that it undertook to endeavor a cultural diplomacy about the History to be taught, impervious to the political instability of that period and culminating with the publication of the "Bibliography of the History of Brazil”.
\end{abstract}

Keywords: History Teaching. School book. Cultural diplomacy. League of Nations. Pan-American Union. 


\section{Referências}

BARACUHY, Braz. A crise da Liga das Nações de 1926: realismo neoclássico, multilateralismo e a natureza da política externa brasileira. Contexto Internacional. Rio de Janeiro, v. 28, n. 2, p.355-397, jul. /dez. 2006. Disponível em:

$<$ http://www.scielo.br/scielo.php?script=sci_arttext\&pid=S0102-85292006000200002>.

Acesso em: 16 jul. 2011.

BECHET, Christophe. La révision pacifiste des manuels scolaires: les enjeux de la mémoire de la guerre 14-18 dnas l'enseignement belge de l'entre-deus-guerres. CHTP, n. 20, jan. 2008. p. $49-101$.

Disponível em: <http://www.schist.ulg.ac.be/biblio/Bechet.pdf>. Acesso em 12 de março de 2011.

CICCHINI, Marco. Un bouillon de culture pour les sciences de l'éducation ? Le Congrès international d'éducation morale (1908-1934). Paedagogica Historica, Genebra, v. 40, n. 56, p. 633-656, out. 2004.

CHARTIER, Roger. Cultura escrita, literatura e história. Tradução: Ernani Rosa. Porto Alegre : Artmed, 2001.

DUMONT, Juliette. Le Brésil de Vargas: entre l’Institut International de Coopération Intellectuelle et l'Union Panaméricaine. $H A L$ : sciences de l'homme et de la societé, Paris, 2010. Disponível em: <http://halshs.archives-

ouvertes.fr/view_by_stamp.php?\&halsid=ikpdmun5dfm2q66f7fadoqgaa0\&label=SHS\&langu e=en\&action_todo=view\&id=halshs-00494010\&version=1>. Acesso em: 23 jul. 2011.

GARCIA, Eugênio Vargas. O Brasil e a Liga das Nações (1919-1926). Porto Alegre: Ed. UFRGS, 2005.

GIUNTELLA, Maria Cristina. Enseignement de l'histoire et revision des manuels scolaires dans l'entre-deux-guerres. In : BAQUÈS, M-C ; BRUTER, A. ; TUTIAUX-GUILON, N. (Org.). Pistes didactiques et chemins d'historiens: textes offerts à Henri Moniot. Paris: L’Harmattan, 2003. p. $161-190$.

GUIMARÃES, Lúcia M. P. Da escola palatina ao silogeu: Instituto Histórico e Geográfico Brasileiro (1889-1938). Rio: Museu da República, 2007.

HOLLANDA, Guy de. Programas e compêndios de história para o ensino secundário brasileiro: 1931-1956. Rio de Janeiro: INEP/ MEC, 1957.

LEITE, Juçara Luzia. Pensando a paz entre as guerras: o lugar do ensino de História nas relações exteriores. Revista Antíteses, Londrina, Ed. UEL, v. 3, p. 1-23, 2010. Disponível em: $<$ http://www.uel.br/revistas/uel/index.php/antiteses/article/view/7925>. Acesso em 20 de jul. de 2011.

LEITE, Juçara Luzia. Intelectuais e professores pensando a paz no período entreguerras. In LEITE, Juçara Luzia; ALVES, Claudia. Intelectuais e História da Educação no Brasil: poder, culturas e políticas. Vitória: EdUFES, 2011. p. 305-334. 
RENOLIET, Jean-Jacques. L'Unesco oubliée: la Société des Nations et la coopération intellectuelle (1919-1946). Paris: Publications de la Sorbonne, 1999.

SANTOS, Luís Cláudio Villafañe G. O dia em que adiaram o Carnaval: política externa e a construção do Brasil. São Paulo: Ed. Unesp, 2010.

SILVA, Alexandra de Mello e Silva. Ideias e política externa: a atuação brasileira na Liga das Nações e na ONU. Revista Brasileira de Política Internacional, v. 41, n. 2, p. 139-158, jul./ dez. 1998. Disponível em:

<http://www.scielo.br/scielo.php?pid=S0034-73291998000200008\&script=sci_arttext $>$. Acesso em: 17 jul. 2011.

UNESCO. La réforme des manuels scolaires et du matériel d'enseignement. Paris: Unesco, 1950.

Recebido em: 15/07/2011

Aprovado em: 05/10/2011 